\title{
The use of an Online Student Query System using an ITIL approach at CPUT, Department of Information Technology
}

\author{
Waldon Hendricks ${ }^{1}$ and W Hendricks ${ }^{2}$ \\ ${ }^{1}$ Affiliation not available \\ ${ }^{2}$ Faculty of Informatics and Design, Cape Peninsula University of Technology
}

June 25, 2021

\begin{abstract}
Student's queries play a significant role in improving the service delivery for IT students at CPUT Department of Information Technology. It is imperative to know how to handle student requests efficiently. Currently student's lodge their complaints, selecting from a list of topics their query gets captured, the student query might not get addressed on time or in a certain time frame to support ITIL-based continual service improvement. This study will look at implementing the key service-level processes of ITIL and discuss how to integrate it successfully.
\end{abstract}

\section{Introduction}

The main objective of this research paper is to discuss the importance of implementing the IT Infrastructure library (ITIL) tools and the processes involved that forms part of the ITIL framework. By adopting ITIL we aim to explore the effect of adopting these processes in the academic Online Student Query System at the Department of IT at CPUT. There has been very limited academic research about the adoption of the IT Infrastructure library (Hochstein et.2005).

To improve academic services to IT academic students, an admin information system was implemented as a tool to assist students with online academic queries.

This study focus on the following: Service Support-Operational levels of the IT infrastructure Library: [1] Service Desk, [2] Incident Management, [3] Problem Management and [4] Change Management. Each student has expectations and needs to receive a good service, so the IT department never knows what to expect from students when they encounter them (Anne, 2009). ITIL can be assigned to any organisation because of its unique structure; organisations can determine how many levels of ITIL they want to implement (ITpreneurs Campus, 2009). Opportunities to benefit from information technologies in educational contexts are reported by several authors: Harasim (Harasim et al., 1995), Puttnam (Puttnam, 1996), and Papert (Papert, 1993).

\section{Background to Research Problem}

Many companies began to adopt ITIL during the mid-1990's (Cengage learning 2014). The ITIL framework was developed by the Central Computer and Telecommunications Agency (CCTA) that's based in the United Kingdom to reduce costs and to improve service delivery (Salié 2004).To improve the quality of student requests and to archive all queries logged, the IT academic department implemented an ITIL based online student query system to improve the quality of services to the students. This article was based on the 
implementation of such a system at the Department of IT at CPUT and to address the key processes to the management staff of the department. Most departments are often seen as silo-based and not process-oriented, many incidents gets escalated to the wrong person and the departments implement too many processes that's not properly integrated which leads to confusion amongst the IT staff (Fry, 2005). To ensure that investments at higher education institutions are constantly available, information technology has become a critical factor. (Göcks \& Kuper, 2007; University of Canterbury, n.d.)

\section{Research Problem}

There appears to be a need to improve the quality of student requests and to archive all queries within the Department of IT at CPUT. The main purpose of this study is to determine the practical impact of implementing ITIL and the commitment of management to adapt these processes within the online Student Query System of the department.

\section{Research Objective}

This study focuses on the following research objectives within the Department of IT:

- To identify the reasons why organisations fail to implement ITIL successfully

- To investigate the advantages, limitations and challenges of the ITIL processes

- To determine the benefit of the ITIL processes in an academic environment

\section{Research Question}

Can the IT Infrastructure Library and its processes be successfully implemented in the Student Online Query System within the Department of IT?

Sub-Questions

- What failures could arise from implementing ITIL processes in the Department of IT?

- What ITIL processes will be implemented on the Online Query System?

- Is there a need for the implementation of ITIL processes?

- Can the current online Student Online Query System improve academic related student matters?

\section{Research Methodology}

Methodology is the research means or practice used to understand and expound on occurrences as they appear in the research field (M. Pandy, 2012). Furthermore the research problem studies the implementation of the service support at operational levels. An empirical study was performed to analyse the levels of ITIL adoption at the Department of IT at CPUT. Research methodology covers the specific techniques used in research studies to select cases, measure and observe social life, gather, interpret and analyse data, and report on findings (Newman, 2011).

Surveys can provide accurate, reliable and valid data when serious efforts and observations are applied (Newman, 2006). The Department of IT student online survey was conducted (see Annexure A) to look at the performance factors of the online student query system as follows:

- Accessibility

- Academic Quality

- Speed of solution 
- Completeness

- Clarity

- Success

- Courtesy

\section{Sampling}

Sampling is defined as a researcher selecting a small set of cases from a large pool and generalising to the population (Newman, 2011). The sample should be a representation of a population to enable generalisations about the population (ibid.).

In non-probability sampling there is a limited knowledge about the research population (Newman, 2011). A non-probability sample technique (haphazard sampling) was used, because our case studies have the same characteristics (they are all IT academic students at the Department of IT at CPUT Cape Town campus). The sampling frame involved students of each domain within the Department of IT at CPUT, the domains are as follows:

- Foundations domain

- Undergraduate domain

- Graduate Domain

- Post graduate Domain

\section{Literature Review}

Understanding ITIL key processes relationships

The Information Technology Infrastructure Library manages the service delivery of IT services and support, therefore it can be defined as a set of best practices to manage the processes in the framework (Boyd, 2005). According to Gartner, the most common mistake organisations make is confusing these processes with the services, which leads to service delivery failure (Ecar, 2009). According to Boyd (2005) incidents and problems are not synonymous. Incidents have an objective to restore a service / task as quickly as possible and an incident only become a problem if the first level of support cannot resolve it. Therefore, problem management reduces the impact of service disruption by diagnosing the primary cause of an incident. To further understand the ITIL process relationships we learned that Boyd (2005) states an incident does not become a problem, but they have a many-to-many relationship see figure1 below.

\section{ITIL Key Process Relationships}

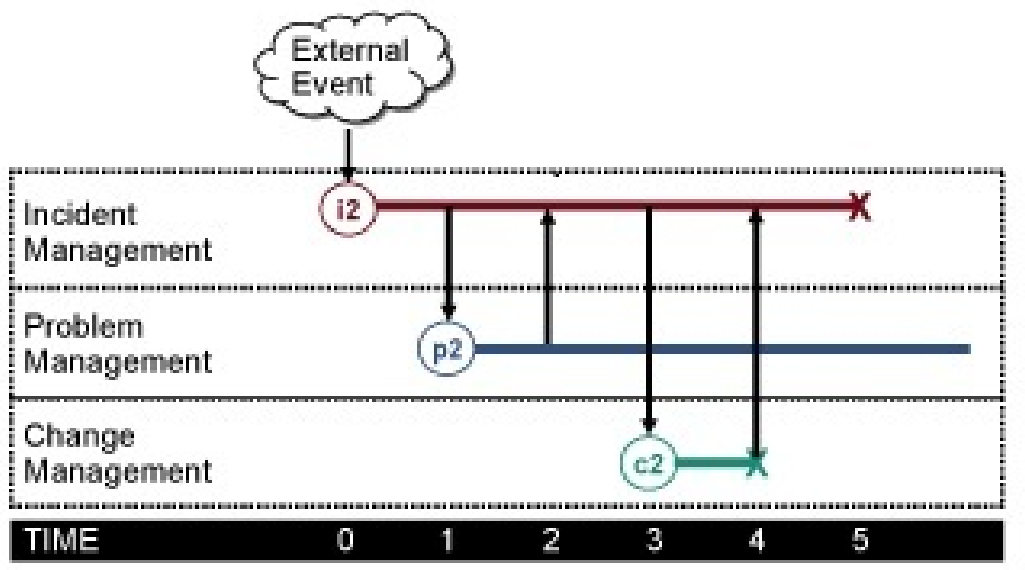


Figure 1: ITIL Key Process Relationships adopted from (Computer economics, 2005)

\section{IT Infrastructure Library (ITIL)}

The Central Computer and Telecommunications agency (CCTA) based in the United Kingdom developed the Government Information Technology Infrastructure Management framework during the serious economic downtown in the late 1980's to reduce costs and to better manage IT service delivery (Sallé, 2004). According to Cater-steel (2006) the Office of Government Commerce (OGC) manages the ITIL framework, which is an independent office of the UK Treasury.

ITIL is the most widely accepted approach to IT Service Management, ITIL also has an integrated approach required by the ISO/IEC 20000 that is based on BS 15000, which was adopted by an ISO member during December 2005. As suggested by Praeg and Schnabel (2006) the IT-service management framework consists of four levels: strategic, business process, IT-service, and tools. ITIL has two different set of components: service delivery, service support, we will focus on the adoption of the service support levels as shown below in table1.

Table1 Description of core ITIL components (adapted from OGC 2006)

Service Desk

Incident Management

Problem Management Change Management
The single point of contact between the service provider and the users. Manages incidents and serv

Manages the lifecycle of all incidents. The primary objective is to return the IT service to users as Manages the lifecycle of all problems. The primary objectives are to prevent incidents from happer Controls the lifecycle of all changes. The objective is to enable beneficial changes to be made with

\section{ITIL implementation failure and the reasons for failure}

According to Fry (2005), we are now in the era where IT failure can severely damage a corporation's image. The organisations become more reliant on using technologies and the need for well-managed services remains increasing. The most common implementation failures of ITIL:

- The lack of management commitment or the drive of a project, managers should be more involved in projects.

- Incidents occur daily so the process diagrams should not be complex but simple maps showing the ITIL processes.

- Not reviewing the escalation rules, priority definitions and the categories.

- Trying to implement too many processes at once causes confusion and poor integration between processes.

- ITIL is a joint venture and the process may cross more than one department, staff should work together as one and not take ownership of process.

\section{Processes}

A process is a collection of work activities that takes a set of inputs to produce a set of outputs (Cengage Learning 2014). Incident management is a process that tracks and resolves incidents; a procedure is the systematic instruction that describes how to perform the tasks in a process.

\section{Incident Management Process}

Incident Management is the process in control for managing the life cycle of incidents as defined by ITIL. See the flowchart for the Department of IT at CPUT. (See Annexure B)

\section{Problem Management Process}


To minimise the impact of the incidents and to remove frequent incidents, are the objectives of Problem Management. Example Flow chart for the Department of IT at CPUT (See Annexure B)

\section{Change Management Process}

The process responsible for monitoring changes within the organisation. This only applies when adding new content to the system. The change management process is necessary when you have to apply a change that affects a large population or users.

\section{Empirical Research Findings of IT Academic Students}

Data was collected from the online survey to see if students can adapt the anytime, anywhere approach to computing that allows them to access information at any time and in any place from multiple computing devices and systems, which is called ubiquitous computing.

Based on the results found, the students felt the Student Query System is not really advertised. They doubt many students are using it or even know about it. They feel the system is basically just an email system alternative, students said the Online Query System needs to be advertised/incorporated more in order for students to really make use of it. (See Annexure A)
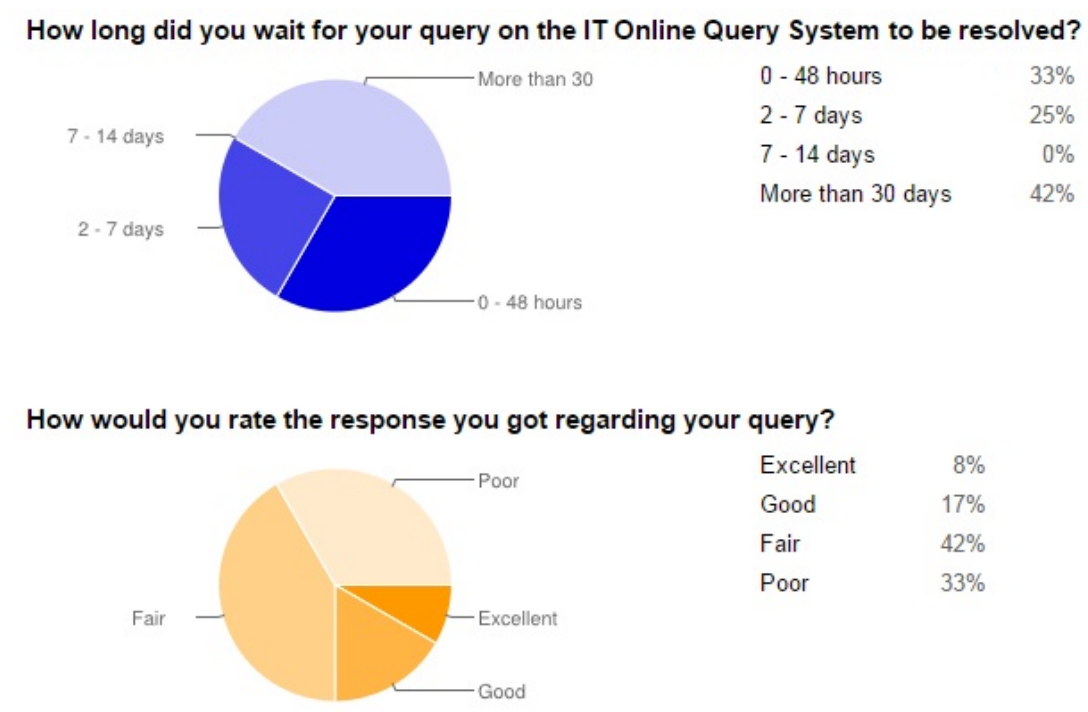
Are you aware that the IT online query system exists?

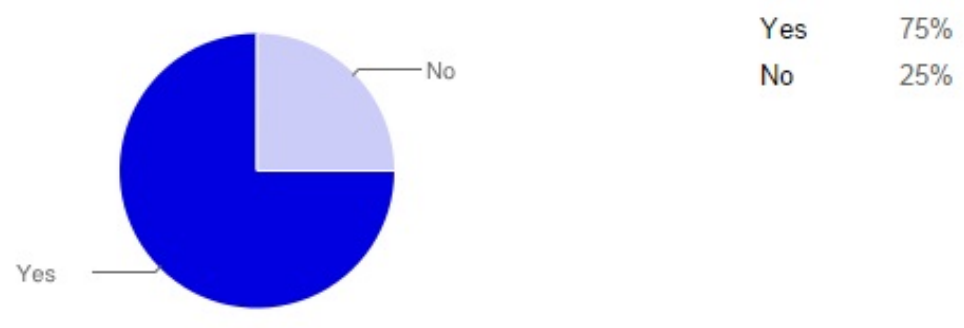

Have you ever used the IT Online Student Query System?

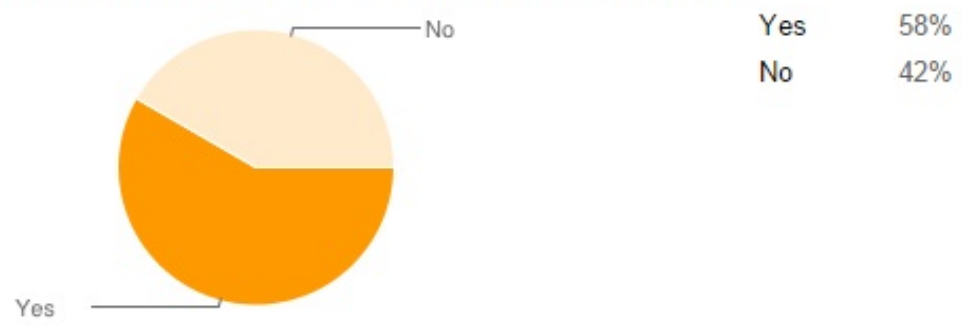

Figure 2

Figure 3

How do you rate this service received by the IT department?

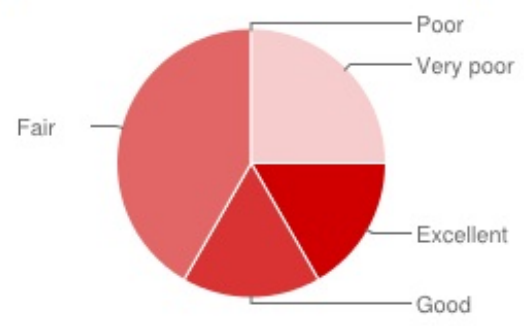

Excellent $\quad 17 \%$

Good $\quad 17 \%$

Fair $\quad 42 \%$

Poor $\quad 0 \%$

Very poor $\quad 25 \%$

Was your query resolved to your satisfaction?

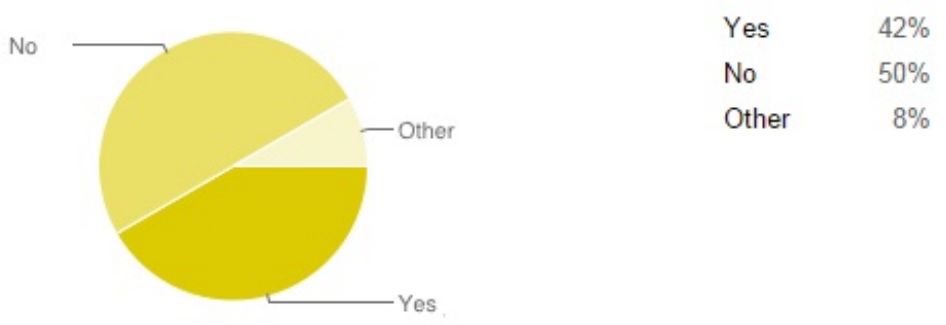

Figure 4 


\section{Limitations of the Study}

The various limitations of this paper include:

- The time constraints involved when conducting this research

- The lack of available academic ITIL implementation resources and literature

- The number of students available to conduct the online survey.

\section{Conclusions}

To conclude the Department of IT at CPUT needs to handle student's queries in a well-timed manner, the online query system is not completely efficient when dealing with student queries or incidents, they need to implement the key ITIL process to improve support to the IT students. Implementing ITIL is not easy and it is common that ITIL implementations end in failures. We looked at proposing Incident Management process and Problem Management process to be applied into the current Student Online Query System.

\section{References}

- Bick, Markus, Kathrin Börgmann, and Agnieszka Anna Onuchowska. "Information Technology Infrastructure Library Intro-duction in the Higher Education Sector-Exploration of the Use of ITIL at European Universities."

- Carcillo, F., et al. "Lessons from adoption of open source trouble ticket system in Turin Municipality to manage citizens' requests." eChallenges, 2010 . IEEE, 2010.

- Carcillo, F., et al. "Lessons from adoption of open source trouble ticket system in Turin Municipality to manage citizens' requests." eChallenges, 2010 . IEEE, 2010.

- Cater-Steel, Aileen and Toleman, Mark (2007). The Role of universities in IT service management education. In: Felix B. Tan and James Thong and Lech J. Janczewski (Eds.). PACIS 2007: Managing Diversity in Digital Enterprises, The University of Auckland Business School \& AUT University, pp. 369-382

- Cater-Steel, Aileen, Mark Toleman, and Wui-Gee Tan. "Transforming IT service management-the ITIL impact." Proceedings of the 17th Australasian Conference on Information Systems (ACIS 2006) . Australasian Association for Information Systems, 2006.

- Cho, Yooncheong, et al. "An analysis of online customer complaints: implications for web complaint management." System Sciences, 2002. HICSS. Proceedings of the 35th Annual Hawaii International Conference on . IEEE, 2002.

- Duffy, Kevin P., and Barbara B. Denison. "Using ITIL to improve IT services." AMCIS 2008 Proceedings (2008): 3.

- Faed, Alireza. "Handling e-complaints in customer complaint management system using FMEA as a qualitative system." Advanced Information Management and Service (IMS), 2010 6th International Conference on . IEEE, 2010.

- Fry, Malcolm. "Top Ten Reasons Organizations are Unsuccessful Implementing ITIL." (2005).

- Grahn, Christian. "Implementing Transparency Logging for an Issue Tracking System." (2012).

- Grahn, Christian. "Implementing Transparency Logging for an Issue Tracking System." (2012).

- Heikkinen, Sanna, et al. "Creating a ITIL-based Software Incident Categorization Model for Measurement: A Case Study." ICSEA 2013, The Eighth International Conference on Software Engineering Advances . 2013.

- Kanapathy, Kanagi, and Kashif Ibadullah Khan. "Assessing the relationship between ITIL implementation progress and firm size: evidence from Malaysia." International Journal of Business and Management 7.2 (2012): p194. 
- Liu, Shuguang, Bo Dong, and Yan Sun. "An ITIL-Based IT Service Management Model for Distance Education." 2013 the International Conference on Education Technology and Information System (ICETIS 2013). Atlantis Press, 2013.

- Open Access Journal of Information Systems. 2014. Open Access Journal of Information Systems. [ONLINE] Available at:http://is.its.ac.id/pubs/oajis/index.php/home/detail/1204/Applying-ITIL-BasedSoftware-Inside-Universitys-ICT-Centre-toward-Continual-Service-Improvement.

- Rimansyah, Muhammad Nanda. A Requirement Model for Customer Complaint System Based on CRM: A Case of Universiti Utara Malaysia. Diss. Universiti Utara Malaysia, 2012.

- Sharifi, Mohammad, et al. "Lessons learned in ITIL implementation failure." Information Technology, 2008. ITSim 2008. International Symposium on . Vol. 1. IEEE, 2008.

- Wan, Stewart HC, and Yuk-Hee Chan. "Improving service management in campus IT operations." Campus-Wide Information Systems 25.1 (2008): 30-49.

- Wang, Jingwen, and Hami Khosravi Sereshki. "How to implement ITIL successfully?." (2010).

\section{Acknowledgments}

Finally thanks to the Cape Peninsula University of Technology (CPUT) Department of IT for allowing me to conduct this research of their current Admin Information System and the IT students for using their time to answer my online survey. Without their cooperation, this research would not have been possible.

\section{Annexes / Appendices}

\section{Annexure A}

\section{IT Department Student Admin IS Survey}

Are you aware that the IT Online Query System exists?

\begin{tabular}{ll}
\hline Yes & $75 \%$ \\
\hline No $\quad 25 \%$ \\
\hline
\end{tabular}

Have you ever used the IT Online Student Query System?

\begin{tabular}{ll}
\hline Yes & $58 \%$ \\
\hline No & $42 \%$ \\
\hline
\end{tabular}

How did you create a ticket on the IT Online student Query system?

\begin{tabular}{ll}
\hline Email & $58 \%$ \\
\hline Cell Phone & $17 \%$ \\
PC in the Lab & $33 \%$ \\
\hline
\end{tabular}

Are you satisfied with the services received using the IT Online Student Query System? 


\begin{tabular}{ll}
\hline Yes & $42 \%$ \\
\hline No $\quad 58 \%$ \\
\hline
\end{tabular}

What do you find most useful and beneficial about using the IT Online Student Query System?

\begin{tabular}{ll}
\hline It's convenient to use & $75 \%$ \\
\hline An easy way to do a query for exam marks or exclusions & $33 \%$ \\
Saves traveling costs & $42 \%$ \\
I can check the responses & $25 \%$ \\
On-line query responded immediately & $8 \%$ \\
Don't have to stand in a queue anymore & $50 \%$ \\
Easy access to the IT student Query System & $17 \%$ \\
Saves on printing cost as query is archived and saved and available on-line & $33 \%$ \\
Allows me to log on to the IT Student Query System and check the progress of my Query & $8 \%$ \\
\hline
\end{tabular}

What are the main reasons preventing you from using the IT Online Student Query System?

\begin{tabular}{ll}
\hline Hard to maneuver on a mobile phone & $33 \%$ \\
\hline Not user friendly & $0 \%$ \\
Difficulties with checking my ticket update status & $8 \%$ \\
Internet is Slow & $42 \%$ \\
None of the above & $33 \%$ \\
\hline
\end{tabular}

How long did you wait for your query on the IT Online Query System to be resolved?

\begin{tabular}{ll}
\hline $0-48$ hours & $33 \%$ \\
\hline $2-7$ days & $25 \%$ \\
$7-14$ days & $0 \%$ \\
More than 30 days & $42 \%$ \\
\hline
\end{tabular}

How would you rate the response you got regarding your query?

\begin{tabular}{ll}
\hline Excellent & $8 \%$ \\
\hline Good & $17 \%$ \\
Fair & $42 \%$ \\
Poor & $33 \%$ \\
\hline
\end{tabular}

How do you rate this service received by the IT department?

\begin{tabular}{ll}
\hline Excellent & $17 \%$ \\
\hline Good & $17 \%$ \\
Fair & $42 \%$ \\
Poor & $0 \%$
\end{tabular}




\begin{tabular}{ll}
\hline Excellent & $17 \%$ \\
\hline Very poor & $25 \%$ \\
\hline
\end{tabular}

Was your query resolved to your satisfaction?

\begin{tabular}{ll}
\hline Yes & $42 \%$ \\
\hline No & $50 \%$ \\
Other & $8 \%$ \\
\hline
\end{tabular}

\section{What suggestions do you have to improve the IT Student Online Query System?}

- Communicate more with the students.

- can streamline certain issues that would not take as long as others

- It's not really advertised so I doubt many people are using it or even know about it. Also it's basically just an email system alternative. I think it needs to be thought through a bit more and it needs to be advertised/incorporated more in order for students to really make use of it.

- more information and immediate responses

- immediate response due to emergency situations to avoid long queues and traveling expenses

- more information and awareness around it

\section{Annexure B}

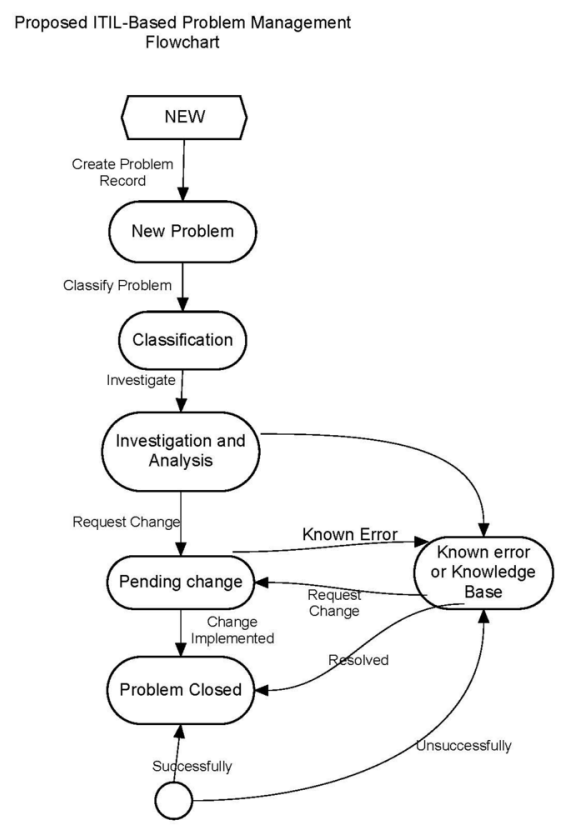




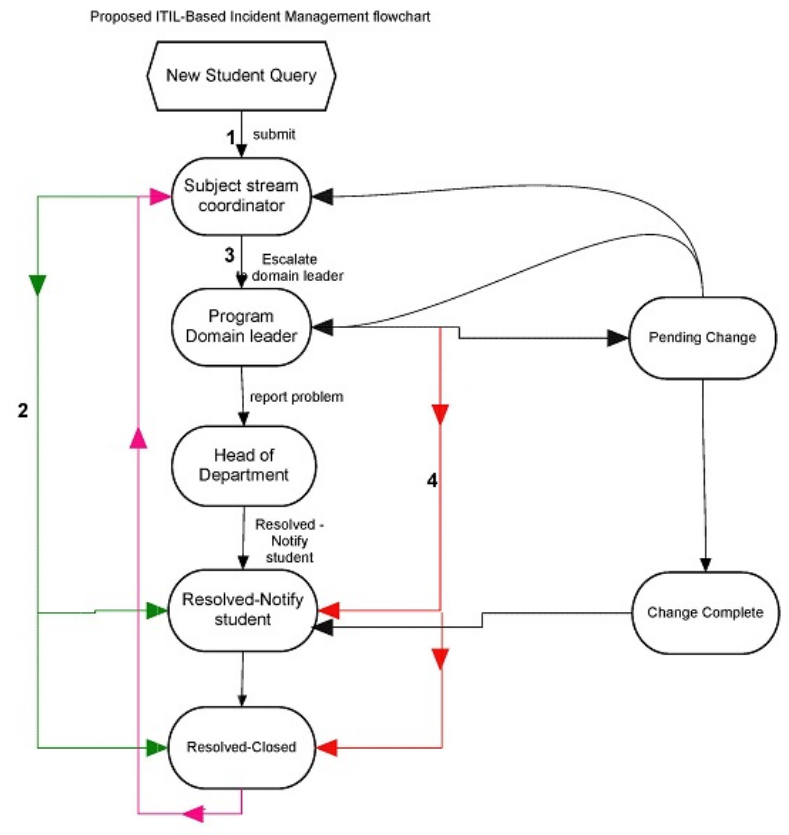

\section{Annexure C}

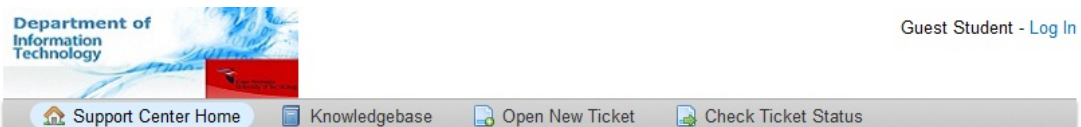

Welcome to the CPUT IT Department Student Query Center

In order to streamline student requests and to better serve you, we utilize a Student Query ticket system. Every student request is assigned a unique ticket number\# which you can use to track your progress and responses online. For your reference we provide complete archives and history of all your student query requests. A valid email address is required to submit a student query.

\section{Open A New Ticket \\ (5) Please provide as much detail as possible so we can best assist you, use a valid CPUT student number and contact number. To update a} previously submitted ticket, please login

Open a New Ticket

\section{Check Ticket Status \\ We provide archives and history of all your current and past student requests complete with responses.}

Check Ticket Status

Be sure to browse our Frequently Asked Questions (FAQs), before opening a ticket. 


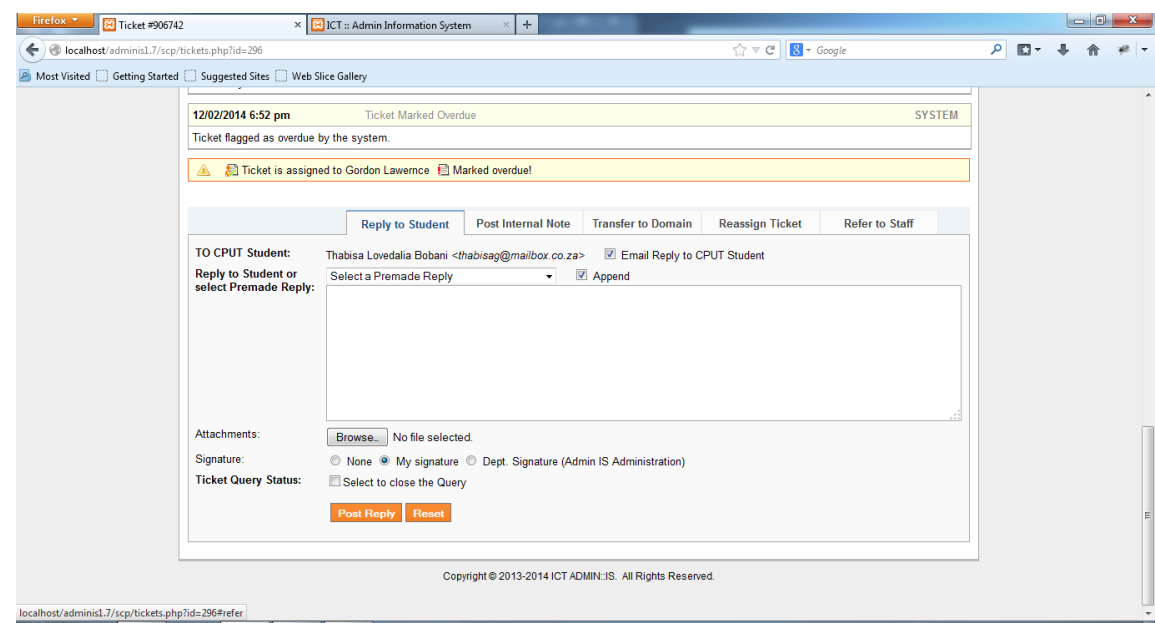

(ifi) है

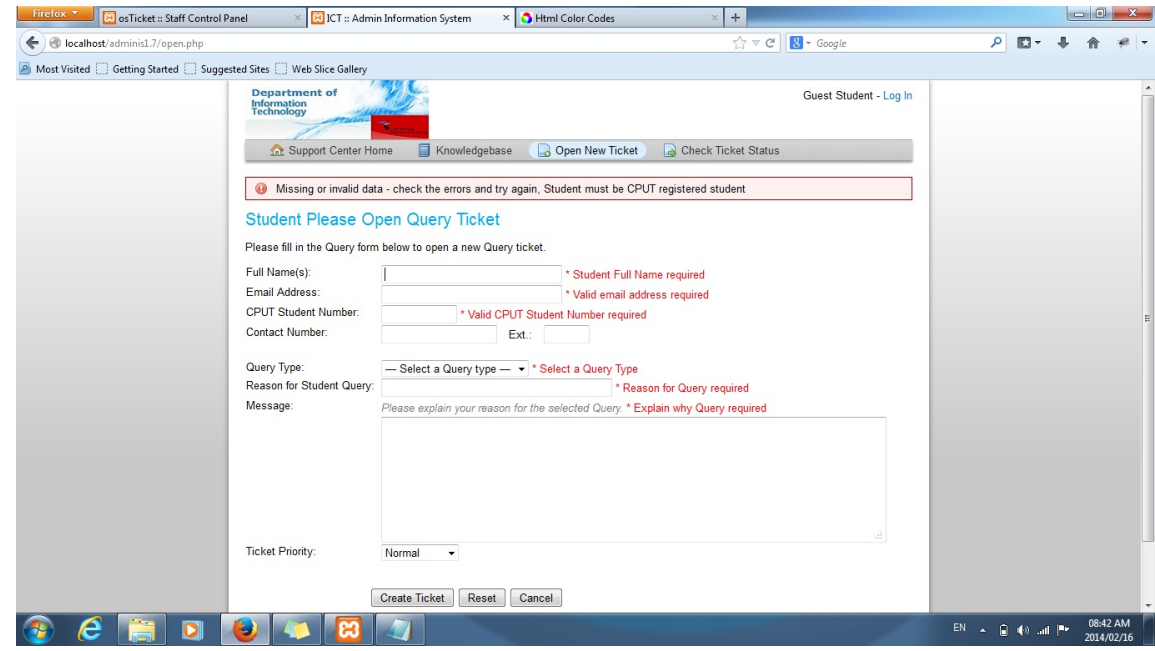

